\title{
Corrigendum: Proximate and Ultimate Perspectives on Romantic Love
}

\author{
Adam Bode ${ }^{\star \dagger}$ and Geoff Kushnick ${ }^{\dagger}$ \\ Human Behavioural Ecology Research Group, School of Archaeology and Anthropology, ANU College of Arts and Social \\ Sciences, The Australian National University, Canberra, ACT, Australia
}

Keywords: romantic love, mechanisms, ontogeny, functions, phylogeny, Tinbergen, human mating, definition

\section{A Corrigendum on}

Proximate and Ultimate Perspectives on Romantic Love

Bode, A., and Kushnick, G. (2021). Front. Psychol. 12:573123. doi: 10.3389/fpsyg.2021.573123

In the original article, there was an error. In the introduction we state "Romantic love serves a variety of functions that vary according to life-stage and duration, including mate choice, courtship, pregnancy, and pair-bonding." In this sentence, "pregnancy" should be "sex."

A correction has been made to Introduction, Paragraph 1. The corrected paragraph is

Edited and reviewed by: Paul J. Watson,

University of New Mexico,

United States

*Correspondence:

Adam Bode

adam.bode@anu.edu.au

tORCID:

Adam Bode

orcid.org/0000-0003-4593-5179

Geoff Kushnick

orcid.org/0000-0001-9280-0213

Specialty section:

This article was submitted to

Evolutionary Psychology,

a section of the journal

Frontiers in Psychology

Received: 14 April 2021

Accepted: 31 May 2021

Published: 24 June 2021

Citation:

Bode A and Kushnick G (2021)

Corrigendum: Proximate and UItimate

Perspectives on Romantic Love.

Front. Psychol. 12:694913.

doi: 10.3389/fpsyg.2021.694913 shown below.

Romantic love is a complex suite of adaptations and by-products that serves a range of functions related to reproduction (Fletcher et al., 2015; Buss, 2019). It often occurs early in a romantic relationship but can lead to long-term mating. It is a universal or near-universal (Jankowiak and Fischer, 1992; Gottschall and Nordlund, 2006; Jankowiak and Paladino, 2008; Fletcher et al., 2015; Buss, 2019; Sorokowski et al., 2020) and is characterized by a range of cognitive, emotional, behavioral, social, genetic, neural, and endocrine activity. It occurs across the lifespan in both sexes. Romantic love serves a variety of functions that vary according to life-stage and duration, including mate choice, courtship, sex, and pair-bonding. Its evolutionary history is probably coupled with the emergence of pair-bonds relatively recently in human evolutionary history.

Additionally, in the original article, there was an error in the subsection "Sex". Here, we stated that "The costs associated with romantic love's reproduction function are far greater for women than for men (Trivers, 1972)." In that sentence, the word "reproduction" should be "sex."

A correction has been made to Ultimate Perspectives, Sex, Paragraph 5. The corrected paragraph is shown below.

The costs associated with romantic love's sex function are far greater for women than for men (Trivers, 1972). Both sexes could be subject to unwanted pregnancy and associated parenting responsibilities (although this impacts women to a greater extent). There is also, however, a risk of damage to an individual's reputation. Women are often subject to criticism from other women for engaging in sexual activity (Koehn and Jonason, 2018), especially if a long-term relationship does not result. Men and women risk damage to their reputation for having sex with a low mate value partner, although men are generally treated far more favorably than women for engaging in sexual activity (see Zaikman and Marks, 2017). For women, a period of pregnancy followed by a lengthy period of lactation may ensue, and this is costly in terms of the ability to obtain sufficient resources and protecting oneself from harm. There is also the possibility that the relationship will 
dissolve following pregnancy and the woman may be left to raise a child without the father's support (Koehn and Jonason, 2018).

\section{REFERENCES}

Buss, D. M. (2019). "The evolution of love in humans," in The New Psychology of Love, 2nd Edn, eds R. J. Sternberg, and K. Sternberg (Cambridge: Cambridge University Press).

Fletcher, G. J. O., Simpson, J. A., Campbell, L., and Overall, N. C. (2015). Pairbonding, romantic love, and evolution: the curious case of Homo sapiens. Perspect. Psychol. Sci. 10, 20-36. doi: 10.1177/1745691614561683

Gottschall, J., and Nordlund, M. (2006). Romantic love: A literary universal? Philos. Liter. 30, 450-470. doi: 10.1353/phl.2006.0030

Jankowiak, W. R., and Fischer, E. F. (1992). A cross-cultural perspective on romantic love. Ethnology 31, 149-155. doi: 10.2307/3773618

Jankowiak, W. R., and Paladino, T. (2008). "Desiring sex, longing for love: A tripartite continuum," in Intimacies: Love and Sex Across Cultures, ed W. R. Jankowiak (New York, NY: Columbia University Press), 1-36.

Koehn, M. A., and Jonason, P. K. (2018). "Costs of short-term mating for women," in Encyclopedia of Evolutionary Psychological Science, eds T. K. Shackelford, and V. A. Weekes-Shackelford (Cham: Springer International Publishing), 1-6.
The authors apologize for these errors and state that they do not change the scientific conclusions of the article in any way. The original article has been updated.

Sorokowski, P., Sorokowska, A., Karwowski, M., Groyecka, A., Aavik, T., Akello, G., et al. (2020). Universality of the triangular theory of love: Adaptation and psychometric properties of the triangular love scale in 25 countries. J. Sex Res. 58, 106-115. doi: 10.1080/00224499.2020.17 87318

Trivers, R. L. (1972). "Parental investment and sexual selection," in Sexual Selection and the Descent of Man, ed B. Campbell (Chicago, IL: Aldine), 136-179.

Zaikman, Y., and Marks, M. J. (2017). Promoting theory-based perspectives in sexual double standard research. Sex Roles 76, 407-420. doi: 10.1007/s11199-016-0677-z

Copyright (c) 2021 Bode and Kushnick. This is an open-access article distributed under the terms of the Creative Commons Attribution License (CC BY). The use, distribution or reproduction in other forums is permitted, provided the original author(s) and the copyright owner(s) are credited and that the original publication in this journal is cited, in accordance with accepted academic practice. No use, distribution or reproduction is permitted which does not comply with these terms. 